EGU2020-5799

https://doi.org/10.5194/egusphere-egu2020-5799

EGU General Assembly 2020

(c) Author(s) 2020. This work is distributed under

the Creative Commons Attribution 4.0 License.

\title{
The impact of the Messinian Salinity Crisis on marine biota
}

\author{
Konstantina Agiadi ${ }^{1}$, Niklas Hohmann ${ }^{2}$, Giorgio Carnevale ${ }^{3}$, Elsa Gliozzi ${ }^{4}$, Constanza Faranda ${ }^{4}$, \\ Francesca Lozar ${ }^{3}$, Mathias Harzhauser ${ }^{5}$, George lliopoulos ${ }^{6}$, Antonio Caruso ${ }^{7}$, George Kontakiotis ${ }^{1}$, \\ Marco Taviani ${ }^{8}$, Alan Maria Mancini ${ }^{3}$, Enrico Borghi ${ }^{9}$, Ildefonso Bajo Campos $^{10}$, Pierre Moissette ${ }^{1}$, \\ Danae Thivaiou ${ }^{1}$, Stergios Zarkogiannis ${ }^{1}$, Eva Besiou ${ }^{1}$, Daniel Garcia-Castellanos ${ }^{11}$, and Angelo \\ Camerlenghi ${ }^{12}$ \\ ${ }^{1}$ Department of Historical Geology and Paleontology, National and Kapodistrian University of Athens, Athens, Greece \\ (kagiadi@geol.uoa.gr) \\ ${ }^{2}$ Friedrich-Alexander-Universität GeoZentrum Nordbayern, Erlangen, Germany \\ ${ }^{3}$ Department of Earth Sciences, University of Torino, Torino, Italy \\ ${ }^{4}$ Dipartimento di Scienze-Sezione Scienze Geologiche, Università Roma 3, Rome, Italy \\ ${ }^{5}$ Natural History Museum, Vienna, Austria \\ ${ }^{6}$ Faculty of Geology, University of Patras, Rio, Greece \\ ${ }^{7}$ Dipartimento di Scienze della Terra e del Mare, Università degli studi di Palermo, Palermo, Italy \\ ${ }^{8}$ University of Bologna, Institute of Marine Science - National Research Council ISMAR-CNR, Bologna, Italy \\ ${ }^{9}$ Società Reggiana di Scienza Naturali \\ ${ }^{10}$ Sección de Paleontología, Museo de Alcalá de Guadaíra, Seville, Spain \\ ${ }^{11}$ ICTJA-CSIC, Barcelona, Spain \\ ${ }^{12}$ OGS Istituto Nazionale di Oceanografia e di Geofisica Sperimentale, Trieste, Italy
}

The Messinian Salinity Crisis (MSC) was the greatest paleoenvironmental perturbation the Mediterranean has ever seen. The literature is abundant in hypotheses on the repercussions of the MSC on organisms. However, all these are based on incomplete and still uncertain scenarios about the MSC evolution, as well as on the assumption that such a paleoenvironmental perturbation must have completely reset marine biota. Having prevailed for many decades now, this assumption has leaked from paleontology and geosciences to biological sciences, with numerous studies taking this scenario for granted instead of using it as a starting hypothesis to be tested. Here, we review and revise the marine fossil record across the Mediterranean from the Tortonian until the Zanclean to follow the current rules of nomenclature, correct misidentifications, and control for stratigraphic misplacements. We examine the composition of marine faunas, both taxonomically and considering the function of each group in the marine ecosystem and the transfer of energy through the marine food web. Specifically, we investigate the following functional groups: 1) primary producers, 2) secondary producers, 3) primary consumers, 4) secondary consumers, and 5) top predators. Our study includes sea grasses, phytoplankton, corals, benthic and planktonic foraminifera, bivalves, gastropods, brachiopods, echinoids, bryozoans, fishes, ostracods, and marine mammals. We calculate biodiversity indexes to provide independent evidence quantifying to what degree the marine fauna underwent: 
- A drop of overall regional biodiversity of the Mediterranean due to environmental stress during the Messinian.

- A taxonomic and functional change between the Tortonian, Messinian, and the Zanclean, that is before and after the MSC, as well as during the precursor events to that actual crisis taking place after the Tortonian/Messinian boundary.

- The onset of the present-day west-to-east decreasing gradient in species richness, which has been related to the sea temperature and productivity gradients and the distance from the Gibraltar connection to the Atlantic. 